\title{
APAKAH DEMOGRAFI DAN MENTOR MASIH PENTING DALAM MENENTUKAN KESUKSESAN KARIR PEGAWAI?
}

\author{
Roosemarina A. Rambe \\ Fakultas Ekonomi Universitas Bengkulu
}

\begin{abstract}
Demographic variables and mentor are known to be related to objective and subjective career success, especially to banking employees. The research objectives are to know the career success of banking employees and to know the relationship between objective career success (salary) and subjective career success (career satisfaction) with the demographic variables (age, sex, education, and marital status) and mentor. The respondents are banking employees in Bengkulu city who have two years work experiences.

Using canonical analysis, it proves that demographic variables and mentor are related to salary and career satisfaction. However, based on canonical loading, out of 5 independent variables, only age, marital status and sex are significant related to salary and career satisfaction.
\end{abstract}

Keyword: objective career success, subjective career success, salary, career satisfaction, demography, mentor.

PENDAHULUAN

Karir seorang pegawai dimulai pada saat pegawai tersebut mulai bekerja, yang dilihat dari jabatan awal yang diduduki dan tercermin pada besarnya gaji awal yang diperoleh. Seiring dengan berjalannya waktu, jabatan dan gaji yang diperoleh seorang pegawai akan mengalami perubahan. Pegawai yang memperoleh karir yang bagus akan menerima jabatan yang lebih tinggi dan gaji yang lebih besar dibandingkan apa yang diperolehnya saat memulai pekerjaan.

Dilihat dari jabatan awal yang diduduki, seperti yang diungkapkan di atas, ternyata pegawai baru wanita menduduki posisi yang lebih baik dari apa yang diperoleh pegawai pria. Selanjutnya dengan jabatan yang lebih baik tersebut, maka gaji awal yang diperoleh pegawai baru wanita lebih tinggi dibandingkan gaji awal yang diterima pegawai baru pria (Rambe, 2003).

Seharusnya, dalam keadaan normal, karena pegawai wanita menduduki posisi awal dan gaji yang lebih tinggi dari pegawai pria, maka untuk selanjutnya posisi dan gaji pegawai wanita tersebut tetap lebih tinggi dari apa yang diterima pegawai pria. Kalau ini terjadi, maka hal ini menunjukkan bahwa pegawai wanita memiliki karir yang sukses. Namun ternyata kesuksesan karir pegawai wanita tidak sebagus yang dicapai oleh pegawai pria (Pierce-Brown dan Richardson, 1995). Rambe (2003) juga menyebutkan bahwa setelah pegawai bekerja beberapa tahun, gaji yang diterima pegawai wanita menjadi lebih rendah dibandingkan pria. Hal yang sama diungkapkan juga oleh Richardson (1996) bahwa akuntan wanita dibayar lebih sedikit dibandingkan akuntan pria. 
Namun demikian, kesuksesan karir tidak hanya diukur dari posisi (jabatan) dan gaji. Kesuksesan karir mengandung dua makna, yaitu sukses karir secara objektif dan subjektif (Jaskolka et al, 1995; Melamed, 1996; Aryee et al, 1994). Kesuksesan karir secara objektif dapat diukur secara mudah seperti posisi kerja dan gaji, sedangkan kesuksesan karir secara subjektif tidak dapat diukur dengan mudah (Nabi, 1999).

Indikator kesuksesan karir secara subjektif (yang tidak dapat diukur secara mudah) adalah tingkat kepuasan seorang pegawai atas karir yang diperolehnya. Misalnya, pegawai wanita yang tidak memiliki kesuksesan karir secara objektif (tercermin melalui jabatan dan gaji yang rendah), namun merasa puas atas karir yang diperolehnya, maka pegawai wanita tersebut memperoleh kesuksesan karir secara subjektif.

Kesuksesan karir untuk masing-masing jenis (objektif saja atau subjektif saja) telah banyak diteliti, namun penelitian pada kedua jenis sukses karir (secara objektif dan subjektif) secara simultan masih jarang dilakukan (Judge et al, 1995). Akan menjadi lebih bermanfaat untuk mengetahui bagaimana kesuksesan karir pegawai baik secara objektif maupun subjektif.

Pada dasarnya, untuk bekerja di industri perbankan, terdapat beberapa profil demografi (seperti jenis kelamin, umur, dan penampilan diri) yang berhubungan dengan awal karir pegawai. Dalam hal jenis kelamin, pada saat mereka diterima bekerja, pegawai baru wanita biasanya ditempatkan pada bidang yang berhubungan dengan nasabah atau dikenal dengan teller atau customer services, sedangkan pegawai baru pria ditempatkan pada bagian yang lain (Rambe, 2003). Usia juga memainkan peranan dalam penentuan jabatan yang dicapai pegawai. Setelah mencapai usia tertentu, pegawai dengan posisi teller atau customer services akan dipindahkan ke bagian back office. Misalnya di Bank Mandiri, teller dan customer service diperuntukkan pegawai berumur di bawah 35 tahun. Faktor lain yang juga ikut menentukan kesuksesan karir adalah status perkawinan (Nabi, 1999), dan mentor (Simonetti, 1999; Burke dan McKeen, 1997; Appelbaum et al, 1995).

Sangat penting juga untuk mengetahui faktor-faktor yang menjadi prediktor kesuksesan karir pegawai perbankan. Dengan mengetahui faktorfaktor tersebut, maka pegawai bank dapat merencanakan karir melalui faktor penentu tersebut.

\section{LANDASAN TEORI}

\section{Kesuksesan Karir}

Terdapat beberapa pengertian karir. Karir adalah suatu deretan posisi yang diduduki oleh seseorang selama perjalanan usianya. Karir juga 
didefinisikan sebagai total pengalaman yang berhubungan dengan kerja sepanjang hidup seseorang (London dan Stumpf, 1982; Robins, 1996; George dan Jones, 1999; Greenberg dan Baron, 1995).

Tidak semua orang bisa memperoleh kesuksesan karir. Kesuksesan karir mengandung dua makna, yaitu kesuksesan karir secara objektif dan kesuksesan karir secara subjektif. Kesuksesan karir secara objektif didefinisikan sebagai tingkat kesuksesan yang dapat diukur dan diamati secara objektif seperti gaji atau kompensasi dan jabatan manajerial (Judge et al, 1995; Jaskolka et al, 1985; Melamed, 1996).

Sementara itu kesuksesan karir secara subjektif merupakan kesuksesan karir yang tidak dapat diukur secara objektif (Nabi, 1999, Judge et al, 1995; Pelluchette, 1993; Jaskolka et al, 1985). Kesuksesan karir secara subjektif dapat diartikan sebagai perasaan yang dimiliki oleh seorang pegawai mengenai karirnya, seperti persepsi pencapaian karir dan prospek masa depan karirnya (Aryee et al, 1994). Individu yang memperoleh kesuksesan berkarir secara subjektif akan merasa lebih bahagia dan merasa lebih sukses dalam karir secara relatif walaupun mereka sebenarnya tidak mencapai standar kerja yang seharusnya. Kesuksesan karir secara subjektif juga dapat diukur melalui persepsi pegawai tentang kesuksesan karir dan kepuasan karir (Burke, 1999; Kirchmeyer, 1998; Parasuraman et al, 1996; Peluchette, 1993).

Selanjutnya kesuksesan karir (baik secara objektif dan subjektif) yang dicapai oleh individu dapat dikategorikan menjadi beberapa golongan. Nabi (1999) menggolongkan pegawai berdasarkan kesuksesan karir (objektif dan subjektif) ke dalam 4 golongan yaitu golongan pemenang (sukses berkarir secara objektif dan subjektif), golongan pemenang subjektif (sukses berkarir secara subjektif, namun tidak sukses secara objektif), golongan korban sukses (sukses berkarir secara objektif namun secara subjektif tidak sukses), dan golongan pegawai frustrasi (tidak sukses berkarir secara objektif dan subjektif).

\section{Faktor Yang Berhubungan Dengan Kesuksesan Karir}

Banyak faktor yang telah diteliti dan memiliki hubungan dengan karir seperti kebijakan dan struktur organisasi (Widiastuti, 2003; Morrison, 1992), dukungan rekan kerja (Burke et al, 1995), jaringan kerja (Burton, 1997; Mann, 1995; Burke et al, 1995). Selain faktor-faktor tersebut, demografi dan mentor termasuk faktor yang diteliti dan diakui kontriusinya dalam menentukan karir seseorang.

Untuk faktor demografi, terdapat beberapa profil demografi yang telah diteliti dan memiliki kontribusi pada karir pegawai seperti umur dan pendidikan. Beberapa ahli menjelaskan adanya hubungan positif antara karir dengan pendidikan dan umur (Powell, 1988; Melamed, 1996; Judge et 
al, 1995; Paisey, 1995). Menurut teori human kapital, seseorang dapat meningkatkan penghasilannya melalui tingkat pendidikan (Simanjuntak, 1998). Hal ini didukung oleh Nabi (1999) yang menemukan bahwa pegawai yang sukses berkarir secara objektif (memperoleh gaji yang tinggi) adalah mereka yang berpendidikan tinggi.

Faktor demografi seperti jenis kelamin juga ikut menentukan pola karir (Nabi, 1999; Lloyd, 1997; Gammie dan Gammie, 1997; Richardson, 1996; Judge et al, 1995; Paisey, 1995). Dilihat dari jenis kelamin, ternyata untuk pegawai wanita yang memiliki kesuksesan dalam karir adalah mereka yang berumur lebih dari 30 tahun (atau antara 30 sampai 35 tahun) dan berpendidikan minimal S2 (Powell, 1988).

Secara umum, pria memiliki sukses karir yang lebih baik daripada wanita (Nabi, 1999; Richardson, 1996; Paisey, 1995, Pierce-Brown dan Richardson, 1995; Jack, 1993; Drain, 1990; Silverstone, 1990). Perbedaan kesuksesan karir antara pria dan wanita berupa karir objektif (Nabi, 1999; Paisey, 1995) dan karir subjektif (Paisey dan Paisey, 1995). Perbedaan kesuksesan karir antara pria dan wanita juga terlihat pada pola karir (Lloyd dan Bereznicki, 1998; Paisey dan Paisey, 1995; Lepine, 1992). Karir pria cenderung untuk meningkat seperti pyramid, sedangkan karir wanita cenderung tidak naik (bergerak horizontal). Selanjutnya dilihat dari pola karir dan dihubungkan dengan jumlah pria dan wanita yang memiliki pola karir tersebut, ternyata pada pola karir fast linear jumlah pria lebih besar dibandingkan jumlah wanita; pada pola karir slow linear jumlah wanita yang lebih banyak daripada pria; pada pola karir static jumlah wanita yang lebih banyak daripada jumlah pria, dan hanya wanita yang memiliki pola downward (Richardson, 1996).

Status perkawinan juga memiliki kontribusi pada kesuksesan karir (Nabi, 1999; Gammie dan Gammie, 1997; Judge et al, 1995; Paisey, 1995; Baur et al, 1993; Davidson and Cooper, 1992; Powell, 1988). Sander (Widiastuti, 2003) menjelaskan beberapa sikap individu yang sudah menikah dalam mengelola hubungan antara karir dan keluarga, yaitu sikap yang berorientasi pada keluarga, menyeimbangkan antara keluarga dan karir, dan berorientasi pada karir. Ada perbedaan sikap antara pria dan wanita yang sudah menikah, yang selanjutnya mengakibatkan terjadinya perbedaan antara pria dan wanita dalam mencapai kesusksesan karir. Bagi pria, pegawai yang sudah menikah menjadi lebih sukses dalam karir secara objektif dibandingkan pria yang belum menikah (Judge dan Bretz, 1994). $\mathrm{Hal}$ ini berkaitan dengan stabilitas, kematangan dan semakin besarnya tanggung jawab yang dipikul pria menikah sebagai kepala keluarga dibandingkan pria yang belum menikah. Namun sebaliknya yang terjadi pada wanita. Wanita menikah yang telah memiliki anak memiliki hambatan yang besar untuk mencapai kesuksesan karir (Soetanto dan Widiastuti, 2003). 
Selain faktor demografi, ternyata mentor diidentifikasi sebagai kontributor penting dalam pekerjaan dan karir. Atau dengan kata lain, mentor merupakan faktor krusial dalam menentukan karir pegawai (George dan Jones, 1999; Simonetti, 1999; Burke and McKeen, 1997; Wentling, 1996; Appelbaum et al, 1995; Gaskill, 1991). Mentor merupakan faktor kunci bagi pegawai untuk mencapai sukses dalam karir dan tetap bertahan pada kesuksesannya.

Mentor didefinisikan oleh Brown (1990) sebagai proses di mana seseorang yang berpengalaman membantu untuk membentuk atau membimbing pendatang baru pada bidang yang sama. Sedangkam Appelbaum et al (1995) menyatakan mentor sebagai perkembangan hubungan dinamis antara dua individu: seorang pembimbing dan seorang yang dibimbing. Mentor dipercaya untuk membimbing individu yang membutuhkan pengarahan tentang peningkatan atau pemikiran dalam membangun perhatian dan tanggung jawab individu tersebut. Mentor dapat membantu pekerja untuk meningkatkan karir melewati tahap-tahap karir. Bahkan dikatakan bahwa pimpinan yang tidak mengarahkan atau mendorong kemajuan karir bawahannya merupakan salah satu penghalang utama dalam kemajuan karir (Wentling, 1996; Gaskill, 1991).

Mentor juga dianggap sebagai faktor yang paling kritikal dalam menjelaskan keterbatasan wanita untuk memperoleh posisi di tingkat manajemen yang tinggi (Smith and Hutchinson, 1995; Burke et al, 1995). Lebih lanjut, Brooks and Brooks (1997) menemukan bahwa pekerja wanita yang mendapatkan mentor (arahan/petunjuk) akan mencapai peningkatan karir yang lebih cepat dibandingkan pekerja wanita yang tidak mendapatkannya. Namun demikian, walaupun mentor merupakan hal penting dalam pengembangan karir wanita tetapi wanita memiliki kesulitan lebih besar daripada pria dalam membangun mentoring dalam karirnya (Widiastuti, 2003).

\section{Kerangka analisis:}

\begin{tabular}{|l|l|l|}
\hline $\begin{array}{l}\text { DEMOGRAFI: } \\
\text { Umur } \\
\text { Pendidikan } \\
\text { Jenis kelamin } \\
\text { Status perkawinan }\end{array}$ \\
\hline \multicolumn{1}{c|}{ Mentor } \\
\hline KEPUASAN KARIR (Subjektif) \\
\hline
\end{tabular}


HIPOTESA

"Ada hubungan antara variabel kesuksesan karir objektif (gaji) dan kesuksesan karir subjektif (kepuasan karir) dengan variabel demografi (umur, pendidikan, jenis kelamin, dan status perkawinan) dan mentor".

\section{METODE PENELITIAN}

Kuesioner diberikan kepada pegawai bank (swasta dan pemerintah) di kota Bengkulu. Metode pengambilan sampel yang digunakan adalah purposive sampling yaitu pegawai bank yang sudah menjadi pegawai tetap bank yang bekerja minimal 2 tahun. Tujuan penentuan sampel ini adalah supaya reponden dapat menjawab dengan benar tentang sukses karir objektif (gaji) dan sukses karir subjektif (kepuasan karir) yang dirasakannya, yang tak bisa dirasakan oleh pegawai yang baru mulai bekerja beberapa bulan. Sampel berjumlah 200 orang.

Alat analisis kanonikal digunakan untuk melihat hubungan sukses karir objektif (gaji) dan sukses karir subjektif (kepuasan karir) dengan variabel demografi dan mentor. Penggunaan alat analisis tersebut dianggap tepat karena penelitian ini menggunakan dua variabel dependen dan lima variabel independen (Hair, 1998).

\section{HASIL PENELITIAN DAN PEMBAHASAN}

\section{Hasil Penelitian}

Setelah dilakukan penyebaran 200 kuesioner kepada responden, ternyata pengembalian kuesioner berjumlah 148 orang (response's rate sebesar 74\%). Beberapa indikator kesuksesan karir dan variabel pendukung dijelaskan di bawah ini. Kesuksesan karir secara objektif ditunjukkan oleh besarnya gaji yang diterima per bulan yang dapat dilihat pada Tabel 1.

Tabel 1. Gaji yang diterima Responden per bulan

\begin{tabular}{|c|c|c|}
\hline Gaji (juta rupiah) & Frekuensi & Persentase \\
\hline $0,5-1,5$ & 23 & 15,5 \\
\hline $1,51-3$ & 70 & 47,3 \\
\hline $3,1-4,5$ & 50 & 33,8 \\
\hline Lebih dari 4,5 & 5 & 3,4 \\
\hline Total & 148 & 100,0 \\
\hline
\end{tabular}

Sumber: Data primer diolah

Gaji terendah yang diterima responden adalah 700 ribu rupiah, sedangkan tertinggi adalah 5,2 juta rupiah, dengan gaji rata-rata responden sebesar 2,75 juta rupiah. Mayoritas responden memperoleh gaji sebesar 1,51 juta - 3 juta rupiah. Dalam hal gaji, secara rata-rata gaji karyawan 
perbankan di Kota Bengkulu lebih tinggi dibandingkan dengan gaji karyawan yang bekerja di sektor swasta di kota yang sama. Dengan jumlah gaji yang diterima oleh responden, maka dapat dikatakan bahwa responden memiliki kemampuan yang cukup untuk menghidupi keluarganya.

Selanjutnya, kesuksesan karir secara subjektif yang digambarkan oleh variabel kepuasan karir dapat dilihat pada Tabel 2. Dengan menggunakan skala Likert (1-5), ternyata kepuasan karir secara rata-rata adalah 2,74 (yang berarti ada sedikit ketidakpuasan atas karir yang dicapai namun mendekati perasaan cukup). Mayoritas responden (sebesar 60\%) merasakan hal yang biasa saja atas karirnya (di antara perasaan tidak puas dan perasaan puas). Lebih memprihatinkan lagi, lebih banyak persentase responden yang menyatakan tidak puas atas karir yang dicapai dibandingkan dengan persentase responden yang puas pada karirnya.

Tabel 2. Kepuasan karir responden

\begin{tabular}{|l|c|c|}
\hline \multicolumn{1}{|c|}{ Kepuasan karir } & Frekuensi & Persentase \\
\hline sangat tdk puas & 10 & 6,8 \\
\hline tdk puas & 34 & 23,0 \\
\hline biasa saja & 89 & 60,1 \\
\hline puas & 14 & 9,5 \\
\hline sangat puas & 1 &, 7 \\
\hline Total & 148 & 100,0 \\
\hline
\end{tabular}

Sumber: Data primer diolah

Banyaknya responden yang menyatakan tidak puas atas karir yang dicapainya dapat disebabkan oleh dua hal, yaitu:

a. Sistem penilaian kinerja. Penilaian kinerja yang memerlukan jangka waktu berkisar 1 sampai 2 tahun, dirasakan oleh sebagian besar responden sebagai penilaian yang tidak adil dari atasan langsungnya. Setelah ada penilaian kerja, selanjutnya pegawai yang memperoleh penilaian baik akan memperoleh promosi. Dengan tidak adilnya penilaian menurut persepsi pegawai yang dinilai, tentu berdampak pada mereka yang memperoleh promosi. Hanya mereka yang memiliki hubungan yang baik dengan atasan yang memperoleh promosi. Sehingga mereka yang merasa mampu tapi diberikan penilaian kerja yang kurang baik (yang menyebabkan tidak adanya promosi ke jabatan yang lebih tinggi) merasakan ketidakpuasan dalam karir.

b. Kondisi perekonomian di Kota Bengkulu yang belum berkembang pesat. Belum berkembangnya perekonomian di kota Bengkulu mengakibatkan pihak Bank belum berani memperbesar operasinya. Hal ini terlihat dari sedikitnya jumlah kantor untuk semua Bank di kota ini. Dari 
14 bank yang ada di Kota Bengkulu pada tahun 2003, hanya terdapat 27 kantor bank (BPS, 2003, hal 370). Sedikitnya jumlah kantor ini berarti pihak Bank hanya memerlukan sedikit orang untuk menduduki jabatan yang tinggi seperti asisten manajer ataupun kepala unit. Padahal, dilihat dari masa kerja dan kinerja sebagian pegawai, mereka seharusnya menduduki jabatan yang tinggi. Hal ini menimbulkan ketidakpuasan dalam berkarir.

Selanjutnya, dengan menggunakan analisis kanonikal, pengujian hipotesa secara statistik dilakukan dengan menggunakan uji $\mathrm{F}$ (multivariate tests). Dengan $\alpha 5 \%$, ternyata $\mathrm{HO}$ ditolak. Ini berarti bahwa ada hubungan antara gaji dan kepuasan karir dengan variabel demografi (umur, pendidikan, jenis kelamin, dan status perkawinan) dan mentor.

Selanjutnya, canonical correlation digunakan untuk mengetahui hubungan secara praktis antara variabel dependen dengan variabel independen. Karena terdapat 2 variabel dalam variabel dependen (gaji dan kepuasan karir), maka terdapat 2 fungsi kanonikal. Fungsi canonical yang signifikan adalah fungsi pertama, di mana koefisien Canonial correlation 0,758 . Ini menunjukkan hubungan yang cukup kuat $(0,758)$ antara variabel independen (umur, pendidikan, jenis kelamin, status perkawinan, dan mentor) dengan variabel dependen (gaji dan kepuasan karir). Dengan kata lain kesuksesan karir pegawai (gaji dan kepuasan karir) berhubungan dengan variabel-variabel independen di atas. Signifikansi secara praktis ini didukung oleh nilai korelasi kanonikal kuadrat (squared Canonical Correlation) sebesar 0,574. Angka ini berarti bahwa dalam fungsi kanonikal yang pertama, 57\% variasi dalam nilai gaji dan kepuasan karir dijelaskan oleh nilai-nilai dari variabel-variabel independen tersebut. Dalam Tabel 3 dijelaskan koefisien canonical loading dari variabel dependen (gaji dan kepuasan karir) dan variabel independen (demografi dan mentor) dari fungsi canonical yang pertama.

Tabel 3. Canonical Loading Dari Fungsi Kanonikal Pertama.

\begin{tabular}{|c|l|c|}
\hline & \multicolumn{1}{|c|}{ Variabel } & Canonical loading \\
\hline & korelasi antara variabel independen dan canonical variates & \\
\hline $\mathrm{X}_{1}$ & Umur & 0,929 \\
\hline $\mathrm{X}_{2}$ & Pendidikan & $-0,073$ \\
\hline $\mathrm{X}_{3}$ & Jenis kelamin & $-0,372$ \\
\hline $\mathrm{X}_{4}$ & Status perkawinan & 0,631 \\
\hline $\mathrm{X}_{5}$ & Mentor & 0,278 \\
\hline & korelasi antara variabel dependen dan canonical variates & \\
\hline $\mathrm{Y}_{1}$ & Gaji & 0,999 \\
\hline $\mathrm{Y}_{2}$ & Kepuasan karir & 0,306 \\
\hline
\end{tabular}

Sumber: Hasil pengolahan SPSS 
Dapat dijelaskan di sini bahwa dari 5 variabel independen ternyata hanya tiga variabel yang signifikan, di mana canonical loading untuk variabel yang signifikan adalah umur $(0,929)$, status perkawinan $(0,619)$, dan jenis kelamin $(-0,381)$. Ini berarti bahwa variabel umur, status perkawinan, dan jenis kelamin berhubungan dengan canonical variate dari variabel independen.

Selanjutnya dari variabel dependen dalam penelitian ini, ternyata kedua variabel tersebut signifikan, dengan canonical loading untuk gaji sebesar 0,999 dan kepuasan karir sebesar 0,306. Berdasarkan koefisien canonical loading (Tabel 3), maka umur merupakan variabel independen yang paling besar kontribusinya dalam menentukan karir, yang diikuti oleh status perkawinan dan jenis kelamin. Sedangkan untuk variabel dependen, maka gaji merupakan variabel yang paling kuat ditentukan oleh keseluruhan variabel independen. Hasil penghitungan tersebut menunjukkan bahwa umur, dan status perkawinan berhubungan positif dengan gaji dan kepuasan karir. Sementara itu, karena koefisien canonical loading jenis kelamin bertanda negatif, maka ini berarti bahwa pria memperoleh gaji dan kepuasan karir yang lebih besar dibandingkan dengan apa yang diperoleh wanita.

\section{Pembahasan}

Hasil penelitian ini menunjukkan bahwa umur, status perkawinan dan jenis kelamin berhubungan dengan gaji (kepuasan karir secara objektif) dan kepuasan karir (kesuksesan karir secara subjektif). Hasil penelitian ini mendukung penelitian-penelitian yang telah dilakukan oleh beberapa ahli.

Umur merupakan variabel yang menentukan kesuksesan karir seseorang. Penemuan ini serupa dengan yang diungkapkan oleh Powell (1988), Nabi (1999), Melamed (1996), Judge et al (1995) dan Paisey (1995). Untuk melihat bagaimana umur menjadi penentu dalam kesuksesan karir ditunjukkan pada Tabel 4 (gaji) dan Tabel 5 (kepuasan karir).

Tabel 4. Gaji dan Umur Responden

\begin{tabular}{|c|c|c|c|c|}
\hline \multirow{2}{*}{ Umur } & \multicolumn{4}{|c|}{ Gaji (juta rupiah) } \\
\cline { 2 - 5 } & $\mathbf{0 , 5 - 1 , 5}$ & $\mathbf{1 , 5 1 - 3}$ & $\mathbf{3 , 1}-\mathbf{4 , 5}$ & $>\mathbf{4 , 5}$ \\
\hline$<25$ th & 2 & 4 & & \\
\hline $26-35$ th & 19 & 59 & 35 & 1 \\
\hline $36-45$ th & 2 & 7 & 12 & 4 \\
\hline $46-55$ th & & & 3 & \\
\hline
\end{tabular}

Sumber: Data primer diolah.

Dari Tabel 4 terlihat adanya hubungan positif antara umur dan gaji. Pada umur di bawah 25 tahun, gaji tertinggi yang diperoleh adalah 3 juta rupiah. Pada kelompok umur 26-35 tahun, ada 1 responden yang memperoleh gaji lebih dari 4,5 juta rupiah, jumlah responden yang berumur 
36 - 45 tahun yang memperoleh gaji lebih dari 4,5 juta rupiah adalah 4 orang. Pentingnya umur dalam kesuksesan karir dapat dipahami, karena semakin tinggi umur seorang pegawai secara tidak langsung juga menunjukkan lamanya masa kerja pegawai tersebut pada tempat kerja tersebut (dalam hal ini bank).

Tabel 5. Kepuasan karir dan Umur Responden

\begin{tabular}{|c|c|c|c|c|c|}
\hline \multirow{2}{*}{ Umur } & \multicolumn{5}{|c|}{ Kepuasan karir } \\
\cline { 2 - 6 } & $\begin{array}{c}\text { Sangat } \\
\text { tidak puas }\end{array}$ & Tidak puas & $\begin{array}{c}\text { Biasa } \\
\text { saja }\end{array}$ & Puas & $\begin{array}{c}\text { Sangat } \\
\text { puas }\end{array}$ \\
\hline & & & & & \\
\hline$<25$ th & 1 & 1 & 4 & & \\
\hline $26-35$ th & 9 & 26 & 71 & 7 & 1 \\
\hline $36-45$ th & & 7 & 11 & 7 & \\
\hline $46-55$ th & & & 3 & & \\
\hline
\end{tabular}

Selanjutnya untuk kesuksesan karir secara subjektif yang diukur melalui kepuasan karir pada Tabel 5 , ternyata responden yang menyatakan puas atas karir yang dicapainya adalah mereka yang berumur antara 26 45 tahun. Secara umum, ada peningkatan kepuasan yang dirasakan atas karir yang dicapai berdasarkan umur (sampai pada umur 26 - 35 tahun). Namun demikian ternyata kepuasan karir tersebut menurun seiring dengan bertambahnya umur. Setelah melewati umur 35 tahun, responden merasakan puas pada karir yang dicapai (kelompok umur 36-45 tahun), dan tidak ada lagi kepuasan pada karir bagi mereka yang berumur lebih dari 45 tahun.

Menurunnya kepuasan karir setelah mencapai umur tertentu sangatlah wajar. Banyak pegawai yang memperoleh karir yang baik dalam usia yang relatif muda. Maka pada tahap selanjutnya di mana umur mereka terus bertambah, mereka berharap akan memperoleh karir yang lebih baik. Namun yang terjadi tidak demikian, karena peningkatan karir mereka mulai melambat seiring dengan bertambahnya umur. Disamping itu, jumlah jabatan manajerial juga terbatas.

Faktor lain yang juga berhubungan dengan kesuksesan karir adalah status perkawinan. Hasil penelitian ini menunjukkan bahwa status perkawinan ikut menentukan kesuksesan karir. Hal ini sesuai dengan penelitian yang dilakukan oleh Nabi (1999), Gammie dan Gammie (1997), Judge et al (1995), Paisey (1995), Baur et al (1993), Davidson dan Cooper (1992), dan Powell (1988). Untuk melihat bagaimana status perkawinan menjadi penentu dalam kesuksesan karir ditunjukkan pada Tabel 6 (gaji) dan Tabel 7 (kepuasan karir). 
Tabel 6. Hubungan gaji dengan status perkawinan

\begin{tabular}{|c|c|c|c|c|}
\hline \multirow{2}{*}{ Status perkawinan } & \multicolumn{4}{|c|}{ Gaji (juta rupiah) } \\
\cline { 2 - 5 } & $\mathbf{0 , 5 - 1 , 5}$ & $\mathbf{1 , 5 1 - 3}$ & $\mathbf{3 , 1}-\mathbf{4 , 5}$ & $\mathbf{7} \mathbf{4 , 5 1}$ \\
\hline belum & 14 & 27 & 10 & \\
\hline menikah & 9 & 43 & 40 & 5 \\
\hline
\end{tabular}

Sumber: Data primer diolah

Dilihat dari status perkawinan, maka Tabel 6 menunjukkan bahwa untuk gaji terendah, lebih banyak persentase responden yang belum menikah (dibandingkan dengan persentase responden yang sudah menikah) yang menerima gaji terendah. Responden yang menerima gaji tertinggi adalah mereka yang sudah menikah. Peningkatan gaji setelah menikah merupakan hal yang wajar, karena mereka yang sudah berkeluarga memiliki kebutuhan yang besar dibandingkan mereka yang belum menikah, sehingga ini menimbulkan motivasi kerja yang lebih tinggi bagi pegawai yang menikah, yang pada akhirnya tercermin pada gaji yang diterimanya. Alasan lain adalah pekerja yang sudah menikah umumnya sudah bekerja cukup lama sehingga mereka memperoleh gaji yang lebih besar.

Tabel 7. Hubungan Kepuasan karir dengan status perkawinan

\begin{tabular}{|c|c|c|c|c|c|}
\hline \multirow{2}{*}{$\begin{array}{c}\text { Status } \\
\text { perkawinan }\end{array}$} & \multicolumn{5}{|c|}{ Kepuasan karir } \\
\cline { 2 - 6 } & $\begin{array}{c}\text { Sangat } \\
\text { tidak puas }\end{array}$ & $\begin{array}{c}\text { Tidak } \\
\text { puas }\end{array}$ & Biasa saja & Puas & $\begin{array}{c}\text { Sangat } \\
\text { puas }\end{array}$ \\
\hline belum & 10 & 14 & 22 & 5 & \\
\hline menikah & & 20 & 67 & 9 & 1 \\
\hline
\end{tabular}

Sumber: Data primer diolah.

Sementara itu, untuk kepuasan karir, dari Tabel 7 terlihat bahwa responden yang merasakan sangat tidak puas pada karir yang dicapai adalah mereka yang belum menikah. Sebaliknya, responden yang menyatakan sangat puas atas pencapaian karir adalah mereka yang sudah menikah. Hal ini senada dengan yang diungkapkan oleh Judge et al (1995) bahwa pria yang menikah dan memiliki anak namun istrinya tidak bekerja di luar rumah menjadi lebih termotivasi untuk bekerja keras sehingga mencapai karir yang bagus. Meningkatnya kepuasan karir setelah menikah dimungkinkan terjadi karena dengan adanya dorongan dari keluarga (istri/suami dan anak) untuk bekerja lebih giat dan memperoleh hasil yang cukup untuk memenuhi kebutuhan hidup sekeluarga. Hal ini menimbulkan ketenangan dalam bekerja, stabil, bertanggung jawab, dan dewasa dalam bertindak. Pada akhirnya semua ini menimbulkan kepuasan pada diri pegawai pria yang menikah tersebut.

Selanjutnya, jenis kelamin juga menentukan kesuksesan karir. Dalam hal gaji, penelitian ini menemukan bahwa pada tingkat gaji terendah, 
lebih bayak persentase wanita yang menerimanya. Sedangkan pada tingkat gaji tertinggi (lebih dari 4,5 juta rupiah), ternyata hanya pria yang mendapatkannya. Dengan kata lain, pria memperoleh gaji lebih besar dari wanita. Untuk melihat bagaimana jenis kelamin menjadi penentu dalam kesuksesan karir ditunjukkan pada Tabel 8 (gaji) dan Tabel 9 (kepuasan karir).

Tabel 8. Hubungan gaji dengan jenis kelamin

\begin{tabular}{|c|c|c|c|c|}
\hline \multirow{2}{*}{ Jenis kelamin } & \multicolumn{4}{|c|}{ Gaji (juta rupiah) } \\
\cline { 2 - 5 } & $\mathbf{0 , 5 - 1 , 5}$ & $\mathbf{1 , 5 1 - 3}$ & $\mathbf{3 , 1} \mathbf{- 4 , 5}$ & $\mathbf{7 4 , 5}$ \\
\hline Jenis kelamin & & & & 5 \\
\hline pria & 9 & 37 & 33 & \\
\hline wanita & 14 & 33 & 17 & \\
\hline
\end{tabular}

Sumber: Data primer diolah

Hasil penelitian ini sesuai dengan pendapat para ahli (Nabi, 1999; Lloyd, 1997; Gammie dan Gammie, 1997; Richardson, 1996; Judge et al, 1995; Paisey, 1995; Morrison, 1992; Powell, 1988). Perbedaan besarnya gaji di mana pria memperoleh gaji lebih besar bila dibandingkan dengan jumlah gaji yang diterima wanita sangat berkaitan dengan jenis dan jabatan pekerjaan yang diperoleh wanita. Hanya sebagian kecil dari wanita yang dipercaya untuk menduduki jabatan menengah ke atas. Kurang suksesnya wanita memperoleh jabatan yang tinggi tercermin pada gaji yang diterima.

Selanjutnya, dalam hal kepuasan karir, dibandingkan pria dan wanita, penelitian ini menemukan bahwa ternyata lebih banyak persentase pria yang menyatakan puas (bahkan sangat puas) pada karir yang telah dicapainya. Hasil penelitian ini mendukung pendapat Paisey (1995) bahwa wanita merasa ketidakpuasan dalam pekerjaan mereka bila dibandingkan dengan apa yang dicapai oleh pria terutama ketika pegawai wanita tersebut memiliki anak.

Tabel 9. Hubungan kepuasan karir dengan jenis kelamin

\begin{tabular}{|c|c|c|c|c|c|}
\hline \multirow{2}{*}{$\begin{array}{c}\text { Jenis } \\
\text { kelamin }\end{array}$} & \multicolumn{5}{|c|}{ Kepuasan karir } \\
\cline { 2 - 6 } & $\begin{array}{c}\text { Sangat } \\
\text { tidak puas }\end{array}$ & Tidak puas & Biasa saja & Puas & $\begin{array}{c}\text { Sangat } \\
\text { puas }\end{array}$ \\
\hline pria & 7 & 23 & 44 & 9 & 1 \\
\hline wanita & 3 & 11 & 45 & 5 & \\
\hline
\end{tabular}

Sumber: Data primer diolah

Kurang suksesnya karir secara subjektif (kepuasan karir) bagi wanita disebabkan karena wanita yang sudah menikah tidak bisa lagi mencurahkan waktu dan perhatian sepenuhnya pada pekerjaan karena harus membagi perhatian dengan keluarga. Ibu yang bekerja dibatasi oleh 
tanggung jawab mengurus keluarga dalam mengejar karirnya dibandingkan dengan suami yang bekerja. Sehingga wanita yang juga menjadi ibu rumah tangga lebih sulit untuk maju dalam pekerjaannya. Padahal mereka merasa mampu untuk menyelesaikan pekerjaan dengan hasil yang lebih baik. Kurang perhatian pada pekerjaan ini yang bukan karena ketidakmampuan dalam bekerja inilah yang menyebabkan sebagian besar wanita tidak puas pada pencapaian karirnya.

Selanjutnya, merujuk pada penelitian yang dilakukan Nabi (1999), penelitian ini juga mengungkap profil pegawai berdasarkan kesuksesan karir (objektif dan subjektif), sebagai berikut:

1. Pemenang (memperoleh gaji tertinggi dan sangat puas pada karir yang dicapai). profil pegawai kelompok ini adalah pria yang sudah menikah, berumur 26 - 35 tahun, dengan pendidikan sarjana, dan menilai bagus atas mentor yang diberikan pimpinan.

2. Pemenang subjektif (sangat puas pada karir tapi gaji rendah). Profil pegawai dalam kategori ini adalah wanita yang belum menikah, berumur 26 - 35 tahun, pendidikan sarjana, dan menilai bagus atas mentor yang diterimanya.

3. Korban sukses (memperoleh gaji tinggi namun tidak puas atas karir yang dicapai). Profil pegawai dalam kategori ini adalah pria yang belum menikah, berumur 26 - 35 tahun, berpendidikan S2, dan menilai cukup atas mentor dari pimpinan.

4. Pegawai frustrasi (gaji paling rendah dan tidak puas atas karir yang dicapai), terdiri dari pria dan wanita. Untuk pegawai pria, belum menikah, berumur 26 - 35 tahun, berpendidikan SMU, dan menilai mentor dengan bagus. Sementara itu untuk pegawai wanita, menikah dan belum menikah, berumur 23 - 35 tahun, berpendidikan S2, dan menilai bagus mentor yang diterimanya.

Dari uraian di atas, terlihat bahwa umur, status perkawinan dan jenis kelamin menjadi penentu dalam kesuksesan karir secara objektif dan subjektif. Dalam penelitian ini ditemukan bahwa pegawai yang paling sukses dalam karir secara objektif (gaji tertinggi dan juga secara subjektif (kepuasan karir yang sangat puas) adalah pria yang sudah menikah, berumur antara 26 - 35 tahun dan berpendidikan sarjana. Penemuan ini hampir sama dengan pendapat Nabi (1999) yang menyatakan bahwa gaji yang tinggi dimiliki oleh pria, berumur sedikit tua, dan berpendidikan tinggi. Selanjutnya khusus untuk pria, dalam penelitian ini, kelompok pemenang dalam karir adalah pria yang menikah, sedangkan kelompok korban sukses dan kelompok pegawai frustasi adalah pria yang belum menikah. Dengan demikian dapat dinyatakan bahwa pria yang menikah lebih sukses dalam karir (gaji lebih tinggi dan memperoleh kepuasan karir yang lebih tinggi) dibandingkan pria yang belum menikah. Hal senada diungkapkan oleh 
Judge dan Bretz (1994), bahwa individu yang menikah memiliki kesuksesan karir yang lebih tinggi daripada individu yang belum menikah.

Sementara itu, untuk pegawai wanita, tidak ada wanita yang memperoleh gaji tertinggi dan tidak ada wanita yang sangat puas atas karir yang dicapainya. Pegawai wanita yang memperoleh gaji pada tingkat menengah (3,01 juta sampai 3,5 juta rupiah) dan puas atas karir yang dicapai adalah wanita yang sudah menikah dengan umur 26 - 35 tahun. Hal senada diungkapkan oleh Powell (1988), di mana wanita yang berkarir bagus adalah mereka yang berumur 30 - 35 tahun dan berpendidikan S2.

Pengelompokan empat kategori kesuksesan karir di atas telah menunjukkan alasan mengapa pendidikan dan mentor tidak signifikan dalam menentukan kesuksesan karir. Untuk pendidikan, ternyata semua responden yang termasuk dalam empat kategori di atas memiliki pendidikan yang cukup tinggi. Sehingga dapat dikatakan bahwa dengan pendidikan yang tinggi, ternyata karir yang dicapai masih beragam, dari yang tidak sukses dalam berkarir sampai pada yang sukses secara objektif dan subjektif. Hal ini dapat dimaklumi karena dalam merekrut pegawai, pihak perbankan tidak membuat standar pendidikan. Bahkan yang banyak terjadi, calon pegawai lulusan sarjana melamar dengan menggunakan ijasah SMU.

Sama seperti pendidikan, dalam penelitian ini terungkap bahwa responden pada berbagai kelompok karir di atas menilai bagus atas mentor yang diberikan pimpinan langsung. Dengan kualitas mentor yang hampir sama inilah yang menyebabkan variabel mentor tidak signifikan dalam menentukan karir pegawai. Selanjutnya karena kurangnya pengetahuan pegawai tentang mentor, walaupun mentornya bagus, pegawai kurang bisa menangkap arahan, pengawasan dan umpan balik yang diberikan pimpinan langsung, yang pada akhirnya mentor tidak menentukan karir mereka.

\section{KESIMPULAN}

Dari kajian di atas, maka dapat disimpulkan bahwa:

1. Secara keseluruhan, ada hubungan antara kesuksesan karir objektif (gaji) dan kesuksesan karir subjektif (kepuasan karir) dengan demografi dan mentor.

2. Dilihat dari masing-masing variabel, dapat dikatakan bahwa demografi dalam hal ini umur, status perkawinan dan jenis kelamin masih menjadi faktor penting dalam menentukan kesuksesan karir (gaji dan kepuasan karir). Sedangkan mentor tidak menjadi faktor penting dalam menentukan kesuksesan karir. 


\section{DAFTAR PUSTAKA}

Appelbaum, S.H., Ritchie, S., dn Shapiro, B.T. (1994). "Mentoring Revisited: An Organizational Behavior Construct". The International Journal of Career Management, 6 (3), 3-10.

Aryee, S., Chay, Y.W. dan Tan, H.H. (1994). "An Examination of the Antecendents of Subjective Career Success Among a Managerial Sample in Singapore', Human Relations, 47 (5), 387-509.

Baur, C., Young, F., and Salway, S.J. (1993, May). "Kids, Cash and Creers", The Scottish Business Insider. hlm 12 - 15.

BPS. (2003). Bengkulu Dalam Angka.

Brooks, Donna and Lynn Brooks. (1997). Seven Secrets of Succesful Female. New York: McGraw-Hill.

Brown, T.L. (1990,Oktober, 1). "Match up with a Mentor". Industry Week, 239, hlm 18.

Burke, R. J. (1999). "Career Success and Personal Failure Feelings Among Managers". Psychological Reports, 184, 651-653.

Burke, Ronald J, Bristor, Julia M., dan Rothstein, Mitchell G. (1995). "The Role of Interpersonal Networks in Female's and Men's Career Development". The International Journal of Career Management, 7 (3), 25-32

Burke, Ronald J. dan Carol A. McKeen. (1997). "Not Every Managerial Female Who Makes It Has a Mentor". Female In Management Review, 12 (4), 136-39.

Burton, Clare. 1997. Female in Public and Private Sector Senior Management, A Research Paper for the Office of the Status of Female Department of the Prime Minister and Cabinet.

Davidson, M.J., and Cooper, C.L. (1992). Shattering the Glass Ceiling. London: Paul Chapman Publishing.

Drain, M. (1990, Juli, 6). "Bridging the Demographic Gap". Journal of Public Finance and Accountancy, hlm 20.

Gammie, Bob., Gammie, Elizabeth. (1997). "Career Progression in Accountancy - the Role of Personal and Situational Factors". Women in Management Review, 12 (5), 167 - 173. 
Gaskill, LuAnn Ricketts. (1991). "Same-sex and Cross-sex Mentoring of Female Proteges. A Comparative Analysis". The Career Development Quarterly, 40 (1, Sept), 48-63.

George, JM., Jones, GR. (1999). Organizational Behavior. Massachusetts: Addison-Wesley. Edisi kedua.

Greenhaus J.H, and S. Parasuraman. (1993). "Job Performance Attributions and Career advancement Prospects: An Examination of Gender and Race Effects". Organizational Behavior and Human Decision Processes, 55 (2), 273-297.

Hair, J.H, et.al. (1998). "Multivariate Data Analysis". New Jersey. PrenticeHall. Edisi kelima. Edisi internasional.

Jack, A. (1993, Oktober, 25). "Number of Women Directors on the Increase". Financial Times, hlm 8.

Jaskolka, G., Beyer, J.M., and Trice, H.M. (1985). "Measuring and Predicting Managerial Success". Journal of Vocational Behavior, 26, 189 $-205$.

Judge, T.A., et al. (1995). "An Empirical Investigation of the Predictors of Executive Career Success", Personnel Psychology, 48, 485-519.

Judge, T. A., \& Bretz, R. D. (1994). "Political Influence Behavior and Career Success". Journal of Management, 20, 43-65.

Kirchmeyer, C. (1998). "Determinants of managerial career success". Journal of Management, 34, 673-692.

Lepine, I (1992)."Making Their Way in the Organization". Women in Management Review, 7 (3).

Linehan, M., H. Scullion and J.S. Walsh. (2001). "Barriers to Women's Participation in International Management". European Business Review. 13 (1), 10 - 18.

Lloyd, Bruce in Discussion with Cathy Bereznicki. (1998). "Careers for the New Millennium". Career Development International, 3/6, 266 270.

London, M., dan Stumpf, S.A. (1982). Managing careers. Reading, MA: Addison-Wesley

Mann, Sandi. 1995. Room at the Top? Human Resource Management International Digest. November/Desember. pp 29-31 
Melamed, T. (1996). "Validation of a Stage Model of Career Success". Applied Psychology: An International Review, 45 (1), 35-65.

Morrison, A.M. (1992). The New Leaders. San Francisco: CA:Jossey-Bass.

Nabi, Ghulam R. (1999). "An Investigation into the differential profile of predictors of objective and subjective career success". Career Development International, 4 (4), 212-224.

Paisey, Catriona., dan Paisey, N.J., (1995). "Career Development of Female Chartered Accountants in Scotland: Marginalisation and Segregation". The International Journal of Career Management, 7 (5), 19-25.

Parasuraman, S., et al. (1996). "Work and Family Variables, Entrepreneurial Career Success, and Psychological Well-being". Journal of Vocational Behavior, 48, 275-300.

Pelluchette, J. (1993). "Subjective Career Success: the Influence of Individual Difference, Fmiliy, dan Organizational Variables". Journal of Vocational Behavior, 43, 198-208.

Pierce-Brown, R., Richardson, C. (1995). "Consolidating the Minority Interest: A Study of Gender Differences in the Careers of Accountants". Occasional Paper Series: Licester Business School. No 26.

Powell, N.G. (1988). Female \& Men in Management. California: Sage Publications, Inc.

Rambe, Roosemarina A. (2003). Peranan Prestasi Akademik dan Kemampuan Non-Akademik Terhadap Keberhasilan Lulusan Universitas Dalam Memperoleh Pekerjaan di Kota Bengkulu. Bengkulu: Laporan Penelitian Fakultas Ekonomi Universitas Bengkulu. Tidak Dipublikasikan.

Richardson, C. (1996). "Snakes and Ladders? The Differing Career Patterns of Male and Female Accountants". Women in Management Review, 11 (4), 13-19.

Robins, Stephen. (1996). Perilaku Organisasi, konsep, kontroversi, aplikasi. Asia: Simon \& Schuster (Asia) Pte. Ltd. Edisi Bahasa Indonesia. Jilid I

Silverstone, R. (1990, September). "Women in Accountancy: ten years only". Accountancy.

Simanjuntak, Payaman J. (2001). Pengantar Ekonomi Sumber Daya Manusia. Jakarta. LPFEUI. Edisi kedua. 
Simonetti, J.L. (1999)."The Key pieces of the Career Survival and Success Puzzle". Career Development International, 4/6, 312-317.

Smith, C.R. and Jacquie Hutchinson. (1995). Gender: A Strategic Management Issue. Sydney: Ligare Pty Ltd.

Soetanto, Yeni Carina, dan Theresia Diah Widiastuti. (2003). "Career Development dan Gender: Bagaimana Persepsi Terhadap Hambatan Struktural dan Sosio Kultural?". Modus. Jurnal Ekonomi dan Bisnis. 15 (2), $141-152$.

Wentling, Rose Mary. (1996). "A Study of Career Development and Aspirations of Female in Middle Management". Human Resource Development Quarterly, 7 (3, Fall), 253-270.

Widiastuti, Imron. (2003). "Wanita Saat Ini, Antara Karir dan Keluarga". Kompetensi. 7 (3), $114-123$ 